\title{
Apleurotropis Girault (Hymenoptera: Eulophidae) new to tropical America, including six new species and biological records
}

\section{CHRISTER HANSSON}

Department of Zoology, Helgonavägen 2, SE-223 62 Lund, Sweden \& Scientific Associate of the Entomology Museum, the Natural History Museum, London, United Kingdom.E-mail: christerdennis@gmail.com

\begin{abstract}
The genus Apleurotropis Girault is here reported for the first time from tropical America. The genus is diagnosed and compared to Achrysocharoides Girault with which it shares important characters. Changes are suggested in two existing keys to Neotropical/Nearctic genera of Eulophidae to include Apleurotropis. Included in Apleurotropis are also six newly described species: A. albicaulis, A. albiscapus, A. anemia, A. assis, A. ficaria, and A. strix, spp. nov., all of which are included in an identification key, diagnosed, described and illustrated. Four of the species have host records: three are parasitoids on leafminers and the fourth species is associated with galls. These new biological records are in accordance with the known host spectrum for this genus.
\end{abstract}

Key words: neotropical, parasitoid, leafminers, galls, gallmakers, identification key, Entedoninae

\section{Introduction}

The genus Apleurotropis Girault is mainly a tropical group previously known only from the Old World. Originally described from Australian species, the morphological concept and distribution of Apleurotropis have been expanded to include additional species from Australia (Girault 1915, 1934, 1935, 1937), India (Surekha \& Narendran 1992), Japan (Kamijo 1977, 1990), Madagascar (Risbec 1952), New Zealand (Bouček 1988), Papua New Guinea (Girault 1938; Kerrich 1974) and Tanzania (Kerrich 1969). Prior to this publication 21 species of Apleurotropis were known, with the majority of species (13) from Australia. Available biological information indicates that the species are mainly primary parasitoids on leafminers belonging to Coleoptera, Diptera, Hymenoptera and Lepidoptera, but some species are associated with galls (for host compilation see Noyes 2001).

Here six new species of Apleurotropis are described from several countries in tropical America, from Mexico to Brazil. These represent the first records of the genus from the Neotropical region. The new Neotropical species fit well into the morphological framework for Apleurotropis put forward by Bouček (1988) and Kamijo (1990) - see diagnosis below. Four of the six species have host records: three of the species have been reared from leafminers and one has been reared from a gallmaker. These records are in accordance with the host range for Apleurotropis.

\section{Morphological abbreviations and acronyms}

$\mathrm{HE}=$ height of eye; HW = height of forewing; $\mathrm{LG}=$ length of gaster; $\mathrm{LM}=$ length of marginal vein; $\mathrm{LW}=$ length of forewing, measured from base of marginal vein to apex of wing; $\mathrm{MM}=$ length of mesosoma; $\mathrm{MS}=$ malar space; $\mathrm{OOL}=$ distance between one posterior ocellus and eye; $\mathrm{PM}=$ length of postmarginal vein; $\mathrm{POL}$ $=$ distance between posterior ocelli $; \mathrm{POO}=$ distance between posterior ocelli and occipital margin $; \mathrm{ST}=$ 